\title{
Mechanical Behavior of Indentation Stress in Carbon Fiber Reinforced Silicon Carbide Composites with Different Densities
}

\author{
Kee Sung Lee ${ }^{\dagger}$ II Kyum Kim, Tae Woo Kim, Seyoung Kim*, In-Sub Han*, and Sang Kuk Woo* \\ School of Mechanical Systems Engineering, Kookmin University, Seoul 136-702, Korea \\ *Energy Materials Center, Korea Institute of Energy Research, Daejeon 305-343, Korea \\ (Received June 8, 2011; Resived June 24, 2011; Accepted July 4, 2011)

\section{서로 다른 밀도를 갖는 탄소섬유강화 탄화규소 복합재료의 압흔응력에 의한 기계적 거동} \\ 이기성 · 김일겸 · 김태우 · 김세영* · 한인섭* · 우상국* \\ 국민대학교 기계시스템공학부 기계설계전공 \\ *한국에너지기술연구원 에너지소재센터 \\ (2011년 6월 8일 접수 ; 2011년 6월 24일 수정 ; 2011년 7월 4일 승인)
}

\begin{abstract}
In this study, we investigated the mechanical behavior of carbon fiber reinforced silicon carbide composites by indentation stress. Relatively porous and dense fiber reinforced ceramic composites were fabricated by liquid silicon infiltration (LSI) process. Densification of fiber composite was controlled by hardening temperature of preform and consecutive LSI process. Load-displacement curves were obtained during indentation of WC sphere on the carbon fiber reinforced silicon carbide composites. The indentation damages at various loads were observed, and the elastic modulus were predicted from unloading curve of load-displacement curve.
\end{abstract}

Key words : Carbon fibers, Ceramic matrix composites, Hertzian contact, Indentation

\section{1. 서 론}

탄소섬유강화 복합재료는 가볍고 기계적 특성이 우수한 장점이 있어서 원자력, 자동차산업, 항공우주용 위성발사체 노즐 등의 부품에 다양하게 적용하기 위해 연구가 지속되고 있다. 탄소/탄소 복합재료는 1960년 및 1970년대에 연구, 개발, 산업화가 진행된 로켓 추진체(rocket propulsion)에서 주된 역할을 하였다. 1980년대에는 세라믹 기지 복합재료 (CMC, Ceramic Matrix Composite)가 발사체(launch vehicles) 의 열적보호시스템(thermal protection system, TPS)에 사용 되었다. 이러한 발사체의 온도는 부위에 따라 $900^{\circ} \mathrm{C}$ 에서 부터 높게는 $1500 \sim 1600^{\circ} \mathrm{C}$ 의 온도에 이르게 되므로 내열성 이 매우 우수하면서도 기계적 신뢰성이 높은 세라믹 복합재 료가 사용되었다. ${ }^{1)}$ 항공우주산업에 대한 기대는 21세기에 들어 더욱 높아지고 있으며, 보다 최근의 에너지 환경문제 의 전 세계적인 정책방향은 항공 우주체의 무게감소, 가

${ }^{\dagger}$ Corresponding author : Kee Sung Lee

E-mail : keeslee@kookmin.ac.kr

Tel : +82-2-910-4834 Fax : +82-2-910-4839
스온도의 향상 필요성을 증가시켰고, $\mathrm{NOx}$ 와 $\mathrm{CO}$ 의 감소 필요성 역시 세라믹스 복합체 개발을 촉진하는 계기가 되 고 있다.2)

그 중에서도 항공우주용 발사체의 노즐부분은 고온, 고 압의 가스가 배출되는 부분이므로 세라믹스의 적용이 기대 되고 있다. 기존에는 몰리브데늄(Mo), 탄탈륨(Ta), 텅스텐 (W) 등이 사용되었으나, 로켓의 효율 및 성능과 관련한 경 량화에 문제가 있고, 고온 가스에 의한 부식 및 마멸저항성 이 낮아 세라믹 복합재가 대체소재로 적용이 연구되고 있 다. 따라서 세라믹 섬유로 강화된 세라믹 복합재료가 주목 받고 있으며, 특히 탄소섬유 (carbon fiber) 로 강화한 탄화규 소 세라믹 기지상 복합소재 (ceramic matrix composites)가 그 후보소재로 대두되고 있다. ${ }^{3,4)}$

로켓 추진기관에서 연소가 일어날 때 온도는 최대 $3000^{\circ} \mathrm{C}$ 이상 오르고 압력도 100 기압 이상에 이른다고 알려져 있 다. 따라서 노즐 부의 일부분이 녹거나 증발되는 삭마 (ablation)현상이 일어나며, 이에 의한 노즐 부품의 열화가 일어나게 된다. ${ }^{5-7)}$ 고체추진체에서는 추진기관의 성능을 높 이기 위해 금속연료로 알루미늄 분말을 약 $20 \%$ 적용하고 
있으며 고온에서 알루미늄이 알루미나 입자로 산화하여 이들의 충돌로 인한 삭마가 일어난다. ${ }^{6)}$ 로켓엔진에 있어서 연소생성물들은 $\mathrm{H}_{2} \mathrm{O}, \mathrm{CO}_{2}, \mathrm{O}_{2}, \mathrm{O}, \mathrm{NO}$ 와 같은 기체들로 구성되며 이러한 기체들은 노즐재인 탄소와 반응할 경우 $\mathrm{CO}$ 가 형성된다. 이러한 반응성분들도 노즐의 삭마를 일으키는 것으로 알려져 있다. 노즐삭마에 영향을 미치는 또 하나의 중요한 변수는 연소압력으로 압력이 증가함에 따라 삭마 율이 증가한다고 보고되고 있다. ${ }^{7)}$

탄소섬유강화 복합소재의 삭마율을 결정하기 위한 방법 에는 실제 로켓 연소시험을 하는 것이나 장비와 시간, 많은 비용이 소요되며, 삭마특성은 열전달, 입자의 침식, 산화 반응, 연소가스의 이온화 및 재결합 등이 복잡하게 관계 되므로, 각 변수들을 독립적으로 구분할 필요가 있다. 따라 서 본 연구에서는 이 중에서도 연소압력에 의한 응력이 작용할 때의 기계적 거동에 관심을 갖고 연구를 수행하 였다. 평가의 방법으로서 압흔(indentation)에 의한 복합재 의 하중-변위 곡선을 얻었고, unloading curve를 이용하여 탄성계수를 예측하였다. ${ }^{8,9}$ 압흔을 가하는 방법은 초경 구 형압자를 이용하여 마이크로 크기 단위의 손상을 발생시 키도록 하중을 변화시켜 일정한 속도로 압흔을 가하여 기 계적 거동을 연구하였다. ${ }^{10)}$ 이러한 국부적인 기계적 손상을 가하여 평가하는 방법은 거시적인 기계적 특성과 연관시킬 경우, 시험편을 따로 제작하거나 파손을 일으키지 않고 그 거동을 예측할 수 있다는 측면에서 많은 장점이 있다. ${ }^{11,12)}$

본 연구에서는 탄소 preform에 탄소 source가 되는 용액 을 함침 시킨 후 $\mathrm{Si}$ 을 용융 침투시켜 $\mathrm{Si}$ 가 $\mathrm{C}$ 와 반응하여 기지상을 채우는 LSI 공정을 이용하여 복합체를 제조한 후, 이 구조체를 연마가공한 후 압흔응력(indentation stress)을 가했을 때 접촉(contact)에 의한 하중-변위(load-displacement) 곡선을 미세구조별로 얻어내어 미세구조가 기계적 거동에 미치는 영향을 고찰하였다. 제조조건에 따라 밀도가 서로 다른 대표적인 두 가지 시험편을 제조하여 압흔에 의한 기계적 거동을 연구하였다.

\section{2. 실험 방법}

\subsection{LSI 공정을 이용한 탄소섬유강화 탄화규소 복합재 제조} 먼저 탄소섬유 $\left(320 \mathrm{~K}\right.$ Oxi-PAN fiber; $1700^{\circ} \mathrm{C}$ 탄화처리, Russia)를 $[0,90]$ 으로 배열 적층한 후 $\mathrm{z}$ 축으로 needle punch preform을 제조하였다. 이 때 섬유체적은 $20 \mathrm{vol} \%$ 로 유 지하였다.

LSI 공정 시 섬유를 보호하기 위한 코팅공정을 위하여, 폭 $30 \mathrm{~mm}$, 두께 $12 \mathrm{~mm}$, 길이 $100 \mathrm{~mm}$ 의 프리폼을 제조한 후, 헥산 : $\mathrm{PCS}=85: 15$ 의 비로 혼합한 용액에 3회 함침하여 표면을 코팅한 후 $1250^{\circ} \mathrm{C}$ 의 온도에서 열처리를 수행하였다.

이와 같이 열처리된 프리폼에 페놀(phenol), 카본블랙 (carbon black), 실리콘( $\mathrm{Si})$ 을 혼합하여 슬러리를 제조하여,
진공챔버 내에서 함침 시켰고, 일정한 온도에서 경화시켰 다. 이 때 각각 서로 다른 온도, 즉 $80^{\circ} \mathrm{C}$ 및 $150^{\circ} \mathrm{C}$ 의 온도 에서 경화시켜서, 상대적으로 dense한 복합재 시험편과 상 대적으로 porous한 복합재 시험편 두 가지 종류의 시험편을 제조하였다. 또한 카본블랙과 실리콘 분말의 비는 $1: 1$ 로 하였고, 카본블랙과 실리콘 분말의 혼합분말이 무게비로 전체의 $20 \%$ 가 되도록 제어하였다.

제조된 경화체는 질소가스 분위기 내에서 $1000^{\circ} \mathrm{C}$ 의 온도 에서 페놀수지의 탄화과정을 거쳤다. 이후 진공 분위기 내 에서 금속 실리콘을 $1700^{\circ} \mathrm{C}$ 의 온도로 상승시켜 융용 침투 시키는 LSI 공정으로 탄소섬유 강화 복합재를 제조하였다.

\section{2. 압흔응력에 의한 기계적 거동 평가}

섬유강화 복합재의 상, 하면을 다이아몬드 $10 \mu \mathrm{m}$ 의 연 마기로 평면 연마하였으며, 복합재의 표면을 $1 \mu \mathrm{m}$ 까지 경 면 연마하였다.

경면 연마된 표면을 광학현미경으로 50 배 및 100 배 확대 관찰하였으며, 이미지 분석기(image analyzer)를 이용하여 전체 면적에 대한 기공의 면적 비를 계산하여 기공률을 측정하였다.

압흔응력에 의한 기계적 거동을 평가하기 위해 반경 $r=$ $3.18 \mathrm{~mm}$ 을 갖는 구형의 초경 볼(tungsten carbide ball, WC)을 준비하였다. 초경 볼을 지그에 부착한 후 만능 하중 시험 기에 장착하였다.

$0.2 \mathrm{~mm} / \mathrm{min}$ 의 일정한 속도로 섬유강화복합재의 표면에 압흔응력을 가하였으며, 최대 하중에 도달한 이후에는 역시 동일한 속도인 $0.2 \mathrm{~mm} / \mathrm{min}$ 으로 하중을 제거하였다. 이 때 미리 장착한 변위센서(displacement sensor)를 이용하여 하 중-변위 곡선을 얻었으며, 이 곡선으로부터 압흔응력에 의 한 기계적 거동을 분석하였다. 특히 본 연구에서는 하중 제거 시의 unloading 곡선에 접선을 그어 접선의 기울기 로부터 탄성계수를 구하였다. 탄성계수 값은 다음의 식을 이용하여 구하였다.

$$
\begin{aligned}
& P=\left(\frac{4}{3} E^{*}\right) R^{\frac{1}{2}} \cdot \delta^{\frac{3}{2}} \\
& \frac{1}{E^{*}}=\frac{1-v^{2}}{E}+\frac{1-v^{\prime 2}}{E^{\prime 2}}
\end{aligned}
$$

위 식에서 $P$ 는 압입하중, $R$ 은 초경구의 반경, $\delta$ 는 침투(변 위)량을 의미하며, $E, E^{\prime}$ 과 $v, v^{\prime}$ 은 각각 시험편과 초경 압 흔 구의 탄성계수와 Poisson 비를 나타낸다.

최대 하중은 시험편에 따라 변경시키면서 실험하였고, 하중에 의한 손상거동을 관찰하기 위하여 $P=0 \sim 4000 \mathrm{~N}$ 의 범위 내에서 시험하였다. 일정한 최대 하중까지 압흔응력 을 가한 후, 표면에 형성된 손상(damage)을 광학현미경(optical microscope, Hanra precision Co., Korea)을 이용하여 50배, 100 배, 200 배의 배율로 관찰한 후 이미지를 $\mathrm{PC}$ 에 저장하였 
다. 이 때 국부적인 소성영역(local plastic zone) 형성여부를 관찰하기 위해 Nomarski illumination을 이용하여 표면의 손상부위를 관찰하였다.

\section{3. 결과 및 고찰}

압흔응력에 의해 기계적 거동을 평가한 상대적으로 porous 하고 dense한 시험편의 미세구조 사진을 다음 Fig. 1에 나 타내었다. (a)의 경우 상대적으로 높은 경화온도에 의해 porous한 복합재 시험편이 제조되었으며, 기공률은 $26.87 \%$ 를 갖는 것으로 측정되었다. 기공은 프리폼에 슬러리를 함침시키는 공정에서 급격한 경화에 의해 형성되며, 그 형상이 구형이기 보다는 섬유의 계면을 따라 이방성적인 (nonisotropic) 모양을 형성하였다. 반면, (b)의 경우 낮은 경화온도에 의해 탄소섬유 주위로 $\mathrm{Si}-\mathrm{SiC}$ 가 상대적으로 치밀하게 충진된 시험편이 얻어졌음을 알 수 있다.

상대적으로 porous하고 dense한 두 가지 시험편에 대해 $P=1000 \mathrm{~N}$ 까지 반경 $r=3.18 \mathrm{~mm}$ 의 초경 구를 이용하여 압 흔응력을 가하고, 이후 $0 \mathrm{~N}$ 까지 일정한 하중을 제거하여 하 중-변위 곡선을 구한 결과를 Fig. 2에 나타내었다. Fig. 2의

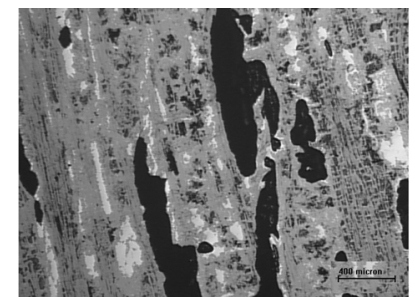

(a)

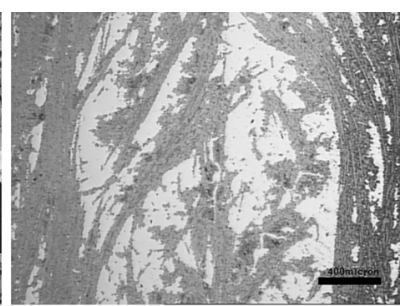

(b)
Fig. 1. The representative microstructure of surface in carbon fiber reinforced composites, (a) relatively porous composite and (b) dense composite.

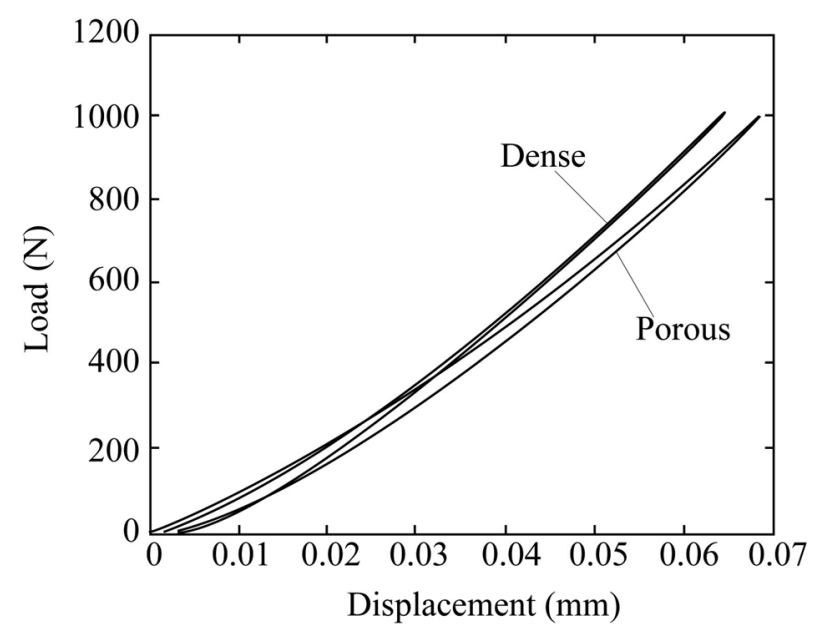

Fig. 2. Load-displacement curve using WC sphere $r=3.18 \mathrm{~mm}$ at load $P=1000 \mathrm{~N}$, for relatively porous and dense composites.
그래프에서와 같이 상대적으로 dense한 탄소섬유강화 복 합재가 보다 탄성적인 거동을 나타내었다. $1000 \mathrm{~N}$ 까지는 두 시험편 모두 시험도중 파손이 일어나지 않았다. 인장, 압축시험 등 거시적인 시험의 경우 선형적인 하중-변위 곡 선을 나타내는 것이 일반적인 데에 비하여, 압흔응력을 가 한 경우는 비선형적으로 하중 증가 시와 제거 시 모두 아래 로 볼록한 형태의 곡선 형태를 나타내었다. 이는 하중-변위 곡선에서 하중이 증가함에 따라 그 하중은 변위의 $3 / 2$ 에 비례한다는 기존의 접촉역학이론과 잘 일치함을 알 수 있다.

$$
P=\mathrm{A} \delta^{3 / 2}
$$

위 식에서 $\mathrm{A}$ 는 상수이다. 본 연구에서는 loading 곡선의 경우, 하중이 변위의 $3 / 2$ 에 비례하여 이론과 비교적 잘 일 치한다는 것을 알 수 있다. 한편, 하중 증가 시와 제거 시 동일하지 않은 곡선을 나타내었는데, 이러한 거동 역시 기 존의 나노 압흔 실험 시 변위센서에 의해 얻을 수 있는 하 중-변위 곡선의 형태와 유사함을 알 수 있다. ${ }^{8)}$ 두 시험편의 하중-변위 곡선을 비교하여 보면, 상대적으로 치밀한 복합 재의 $1000 \mathrm{~N}$ 하에서의 변형률이 porous한 복합재의 변형 률보다 작다는 것을 알 수 있으며, 이는 porous한 탄소섬유 강화 복합재에 비하여 dense한 시험편의 경우가 하중 증가 시의 하중-변위 곡선의 기울기가 더 크다는 것을 의미하며, 그 이유는 기공율의 감소로 복합재의 탄성이 증가한데 기 인한다. 또 loading-unloading 곡선의 모양은 유사하나, 각 각의 두 곡선간의 차이는 dense한 경우가 더 작게 나타났으 며, 이러한 결과 역시 기공률, 즉 밀도의 차이가 기계적 거동에 영향을 미치기 때문으로 생각된다. 두 그래프의 비교를 통해 porous한 복합재의 경우, 상대적으로 많은 에너 지가 흡수되었다가 방출되는데, (loading곡선 밑, unloading곡 선 위에 해당하는 면적만큼) 이는 pore의 영향으로 생각 된다.

두 가지 시험편에 대해 동일한 초경 볼을 사용하여 하 중을 좀 더 증가시켜 하중-변위 곡선을 얻은 결과를 Fig. 3 에 나타내었다. 그림의 (a)에서와 같이 porous한 시험편의 경우, 상대적으로 많은 양의 에너지가 흡수되었다가 방출 되는 거동을 보였으며, $2000 \mathrm{~N}$ 미만에서 균열이 발생되어 하중이 감소하다가 다시 증가하는 거동을 나타내었다. 반 면, 상대적으로 dense한 시험편의 경우는 $P=2000 \mathrm{~N}$ 까지 하 중을 충분히 지지하는 것을 알 수 있으며, 에너지의 흡수 및 방출량이 작다. 또한 보다 하중을 증가할 경우 (b)에서와 같이 $3000-3500 \mathrm{~N}$ 사이에서 하중의 감소가 일어나다가 이 후 $4000 \mathrm{~N}$ 까지 하중이 다시 증가하였다. 이러한 결과는 상 대적으로 치밀한 복합재 시험편이 압흔하중에 대한 내구 성이 보다 우수함을 의미한다. Fig. 3(a)의 그래프에서 하중 -변위 곡선의 접선의 기울기로부터 두 가지 시험편, 즉 상 대적으로 porous한 시험편 및 상대적으로 치밀한 탄소섬 유강화 탄화규소 복합재의 탄성계수를 계산하였다. 하중- 


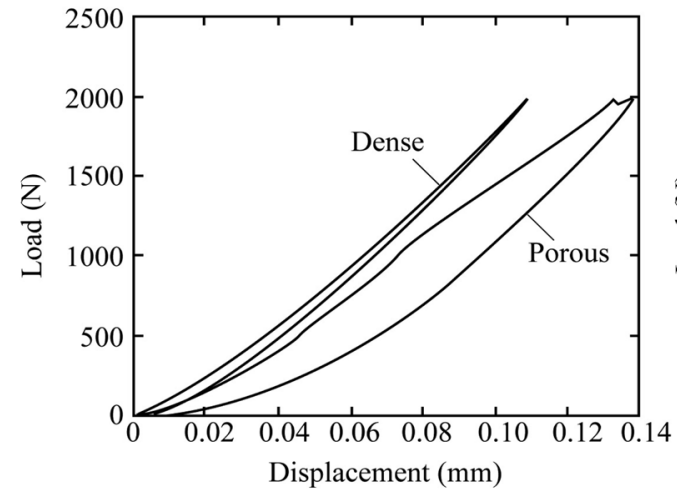

(a)

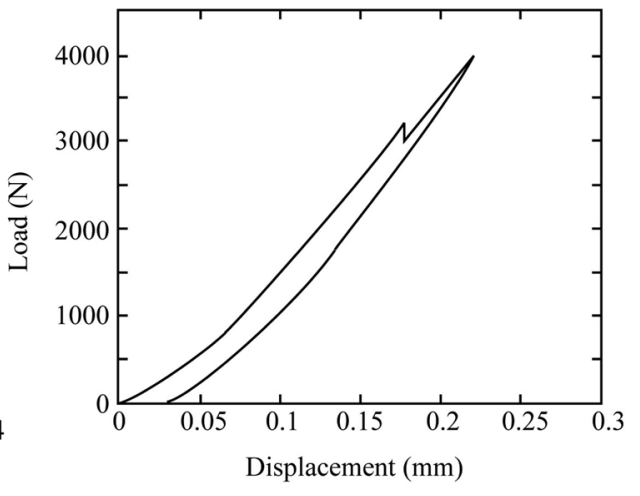

(b)

Fig. 3. Load-displacement curve using WC sphere $r=3.18 \mathrm{~mm}$ (a) at load $P \sim 2000 \mathrm{~N}$ for porous \& dense composites and (b) at load $P=4000 \mathrm{~N}$ for dense composites.

변위 곡선의 unloading curve의 접선의 기울기로부터 계산 된 탄성계수 값은 porous한 복합재의 경우 $E=200 \mathrm{GPa}$, 치 밀한 복합재의 경우 $E=386 \mathrm{GPa}$ 로 계산되었다.

경면 연마된 porous한 탄화규소 복합재의 표면을 반경 $r=3.18 \mathrm{~mm}$ 의 초경 구형압자를 이용하여 $P=1000 \mathrm{~N}$ 과 $P=2000 \mathrm{~N}$ 의 힘으로 각각 압흔응력을 발생시킨 후, 표면에 형성된 손상(damage)을 광학현미경으로 관찰한 사진을 Fig. 4의 (a)와 (b)에 각각 나타내었다. 상대적으로 porous 한 복합재의 경우, $P=1000 \mathrm{~N}$ 까지는 압흔영역 주위로 원 형(ring)의 균열(crack)만 발생하다가 $P=2000 \mathrm{~N}$ 에서 큰 damage가 형성되었다. 균열만이 관찰되고, 압흔에 의한 소 성영역(plastic damage zone)은 관찰되지 않았는데 이는 복 합재가 높은 경도 값과 탄성계수를 갖고 있다는 것을 나타 낸다. $P=2000 \mathrm{~N}$ 의 하중 하에서 형성된 큰 손상은, pore에 의해 하중이 지지되지 못하고 상대적으로 큰 응력이 발생 하여 압흔영역 내에서 기공영역이 붕괴(collapse)되면서 방 사성 균열(radial crack)이 형성됨을 알 수 있다.

Fig. 5에는 치밀한 탄화규소 복합재에 형성된 압흔에 의한 손상(damage)을 관찰한 광학현미경 사진을 나타내었다. 이 때 가해준 하중은 각각 (a) $P=3500 \mathrm{~N}$, (b) $P=4000 \mathrm{~N}$ 으로 서 porous한 시험편 보다 큰 하중을 가한 결과이다. 사진

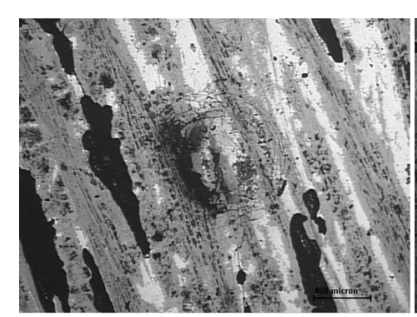

(a)

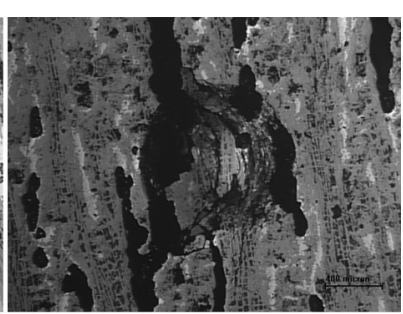

(b)
Fig. 4. Optical micrographs of surface damage in porous composites by indentation of WC sphere $r=3.18 \mathrm{~mm}$ (a) at load $P=$ $1000 \mathrm{~N}$ and (b) $P=2000 \mathrm{~N}$.

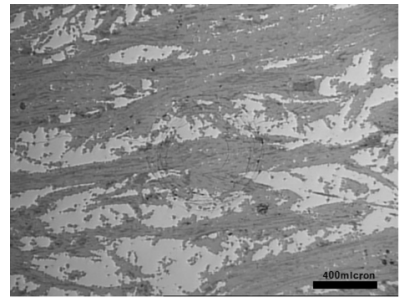

(a)

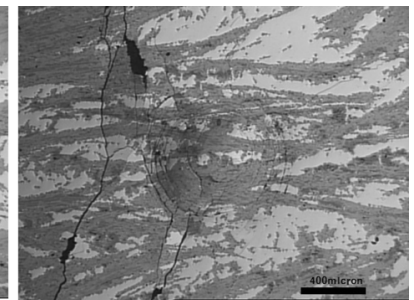

(b)
Fig .5 .Optical micrographs of surface damage in dense composites by indentation of WC sphere $r=3.18 \mathrm{~mm}$ (a) at load $P=$ $3500 \mathrm{~N}$ and (b) $P=4000 \mathrm{~N}$.

에서와 같이 $P=4000 \mathrm{~N}$ 까지도 압흔에 의한 소성영역이 관 찰되지 않았으며, $P=3000 \mathrm{~N}$ 에서는 압흔영역 주위로 원 형(ring)의 균열만이, $P=4000 \mathrm{~N}$ 에서는 방사성 균열(radial crack)이 원형 균열과 함께 관찰되었다. 압흔에 의한 소성 영역이 관찰되지 않았다는 것은 압흔을 가하는 표면 바 로 밑 부분에 작용하는 최대 전단응력에 대한 복합재의 내 구성이 매우 높다는 것을 나타낸다. 이러한 결과는, 기지 상을 형성하는 탄화규소 $(\mathrm{SiC})$ 의 경도가 매우 높다고 알려 져 있으며 일부 미 반응된 잔류 $\mathrm{Si}$ 역시 취성이 높아 압흔 에 의한 항복(yield)에 대한 저항성이 높은데 기인한 것으 로 생각된다.

두 가지 시험편의 표면, 즉 상대적으로 porous한 시험편 및 상대적으로 치밀한 탄소섬유강화 탄화규소 복합재의 각 표면에, 반경 $r=3.18 \mathrm{~mm}$ 의 초경 구형압자를 이용하여 동 일한 하중 $P=2000 \mathrm{~N}$ 까지 압흔하중을 가하였을 때 형성된 손상을 보다 확대하여 Fig. 6에 비교하였다. 동일한 조성의 재질, 동일한 하중을 가했음에도, 기공율(밀도)의 차이에 의 해 나타난 압흔응력에 의한 손상은 그 차이가 매우 뚜렷함 을 알 수 있다. 따라서 항공우주용 노즐재료에 적용 시 삭 마에 의한 마모저항성을 높이기 위해서는 복합재에 기공이 형성되지 않도록 제조하는 것이 중요함을 알 수 있다. 이는 


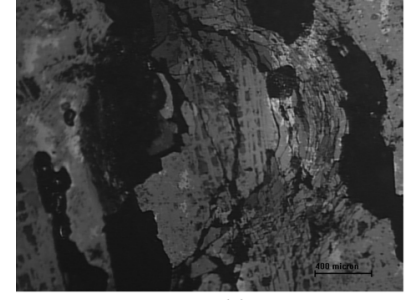

(a)

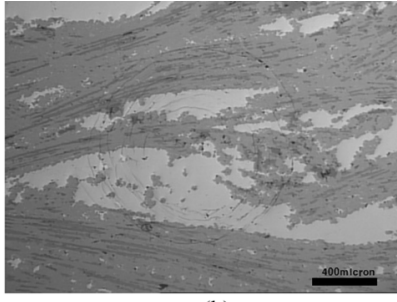

(b)
Fig. 6. Optical micrographs of surface damage by indentation of WC sphere $r=3.18 \mathrm{~mm}$ at the same load $P=2000 \mathrm{~N}$, (a) relatively porous composite and (b) dense composite.

복합재에 기공이 다량 포함되어 있을 경우 동일한 하중 또는 입자충격 하에서 쉽게 마멸이 일어나 내구성의 저 하가 일어날 것이기 때문이다.

\section{4. 결 론}

항공우주용 노즐재의 기계적 압력에 의한 삭마거동을 살 펴보기 위하여, 상대적으로 porous하고 치밀한 탄소섬유 강 화 복합재 시험편을 슬러리 함침 및 LSI 공정을 통하여 제 조하였다. 광학 현미경을 통해 상대적으로 porous하고 치밀 한 조직이 형성됨을 확인하였는데, 기공율이 $26.87 \%$ 인 복합 재와 소결밀도가 $99 \%$ 이상인 치밀한 복합재를 제작하였다. 기계적 거동을 평가하기 위해 초경 구형압자를 이용하여 일 정한 속도로 복합재 시험편의 표면을 일정한 하중까지 압흔 (indentation)하였다가 동일한 속도로 하중을 제거하였고, 이 때 변위센서를 이용하여 하중-변위 곡선을 얻어내었다. 압흔 후 에 표면에 형성된 손상(damage)을 광학현미경으로 관찰하 였고, 하중-변위 곡선을 분석하여 탄성계수를 예측하였다.

그 결과 loading 곡선의 경우, 하중이 변위의 $3 / 2$ 에 비례 하여 증가하였으나, unloading 곡선의 경우는 하중의 변위 의존성에 차이를 나타내어 loading 곡선을 따라 감소하지 않았다. 압흔에 의한 손상을 관찰한 결과 압흔에 의한 소성 영역(plastic damage zone)은 관찰되지 않았는데 이는 복합 재가 높은 경도 값과 탄성계수를 갖고 있다는 것을 나타 내며, 일부 미 반응된 잔류 $\mathrm{Si}$ 역시 취성이 높아 압흔에 의 한 항복(yield)에 대한 저항성이 높은데 기인한 것으로 생각 된다. 상대적으로 치밀한 복합재의 경우 보다 탄성적인 하 중-변위 곡선을 나타내었고, 동일한 하중 하에서의 damage 크기가 작았고, 하중-변위 곡선의 unloading curve의 접선의 기울기로부터 구한 탄성계수 값은 $386 \mathrm{GPa}$ 로 porous한 경 우보다 높았다. 이상의 결과로부터 상대적으로 치밀한 복 합재의 경우가 항공우주용 노즐재로 사용될 경우, 압력에 의한 내구성이 보다 높을 것으로 평가되었다.

\section{Acknowledgment}

본 논문은 2010-2011년도 교육과학기술부의 우주핵심기 술개발사업의 연구개발비의 지원금으로 수행된 연구결과 이며, 이에 감사드립니다.

\section{REFERENCES}

1. W. Krenkel, Ceramic Matrix Composites - Fiber Reinforced Ceramics and Their Applications; Wiley-VCH Verlag GmBH \& Co., Germany, 2008.

2. S. K. Woo, I. S. Han, S. Kim, and K. S. Lee, "Fabrication Technology of Preform in Fiber Reinforced Composites for Aeronautical Applications," Ceramist, 12 [1] 83-92 (2009).

3. K. S. Jang, E. Lee, T. W. Kim, I. S. Han, S. K. Woo, and K. S. Lee, "Mechanical Behavior of $\mathrm{SiC}_{\mathrm{f}}$ Reinforced $\mathrm{SiC}$ Composites with Fiber Coating - Stress Alleviation in SiC fiber by Soft Coating Layer," J. Ceram. Soc. Jpn., 117 [5] 582-7 (2009).

4. Y. H. Ji, I. S. han, S. Kim, D. W. Seo, K. S. Hong, and S. K. Woo, "Effects of Carbon Fiber Arrangement on Properties of LSI C $\mathrm{C}_{\mathrm{f}}$-Si-SiC Composites," J. Kor. Ceram. Soc., 45 [9] 561-66 (2008).

5. J. Lee, K. M. Chun, T. H. Lee, J. C. Bae, and H. C. Ham, "Numerical Analysis of 1-D Ablation and Charring of a Composite Heat Insulator using Finite Analytic Method," pp. 116-120, Proceedings of the KSME 1991 Spring Annual Meeting, 1991.

6. K. Y. Hwang, Y. J. Yim, and H. C. Ham, "Effects of Aluminum Oxide Particles on the Erosion of Nozzle Liner for Solid Rocket Motors," J. Kor. Soc. for Aeronaut. \& Space Sci., 34 [8] 95-103 (2006).

7. B. H. Kim, J. W. Kim, H. H. Park, and Y. Kim, “ATJ Graphite Nozzle Ablation Characteristic on the Operating Condition of Liquid Rocket," pp. 725-29, Proceedings of the Kor. Soc. for Aeronaut. \& Space Sci., 2000 Fall Annual Meeting, 2000.

8. W. C. Oliver and G M. Pharr, "An Improved Technique for Determining Hardness and Elastic Modulus using Load and Displacement Sensing Indentation Experiments," J. Mater. Res., 7 1564-83 (1992).

9. S. W. Kim, D.-M. Kim, S. H. Kang, H.-J. Kim, and H.-T. Kim, "Hardness of Constitutent Phases in $\operatorname{Ti}\left(\mathrm{C}_{0.7} \mathrm{~N}_{0.3}\right)$-WCNi Cermets Measured by Nanoindentation," J. Kor. Ceram. Soc., 46 [1] 116-21 (2009).

10. B. R. Lawn, "Indentation of Ceramics with Spheres : A Century after Hertz," J. Am. Ceram. Soc., 81 [8] 1977-94 (1998).

11. J. H. Ahn and D. Kwon, "Derivation of Plastic Stress-Strain Relationship from Ball Indentations : Examination of Strain Definition and Pileup Effect," J. Mater. Res., 16 3170-8 (2001).

12. F. M. Haggag, "In-Situ Measurements of Mechanical Properties using Novel Automated Ball Indentation System," pp. 27-44 in Small Specimen Test Techniques Applied to Nuclear Reactor Thermal Annealing and Plant Life Extension, ASTM STP 1204, Ed. by W. R. Corwin, F. M. Haggag and W. L. Server, American Society for Testing and Materials, Philadelphia, 1993. 